\title{
THE RELATIVE DETECTION EFFICIENCY CALIBRATION OF A Ge(Li) DETECTOR AT LOW ENERGIES
}

\author{
D. P. DONNELLY and M. L. WIEDENBECK
}

Physics Department, University of Michigan, Ann Arbor, Michigan, U.S.A.

Received 25 April 1968

The relative detection efficiency of gamma-ray full energy peaks in the energy region $20-100 \mathrm{keV}$ was determined using a modified pair-point method. An overall accuracy of $15 \%$ was obtained in this energy region.

\section{Introduction}

A method often used in the calibration of the relative detection efficiency for a $\mathrm{Ge}(\mathrm{Li})$ detector is the pairpoint method. This method relies on the values of relative gamma-ray emission rates for pairs of gamma rays; from a comparison of the full energy peak areas and using the known emission rates, the relative detection efficiency can be determined. This method is generally limited to energies above $100 \mathrm{keV}$. However, using a modified pair-point technique described below, it can be extended to lower energies. Instead of utilizing a source which yields a pair of gamma rays with known emission rates, a source is used which involves deexcitation from only one level in the daughter nucleus. A comparison is then made of the relative peak areas of the gamma ray and the $\mathrm{K} \mathrm{X}$-rays which follow the internal conversion process. With a knowledge of the internal conversion coefficient and fluorescent yield, the "relative emission rates" of the gamma ray and $\mathrm{K}$ $\mathrm{X}$-rays can be determined. (If the source decays by electron capture, corrections must be made.) By this technique, the lower limit of a calibration curve can be extended downwards to about $20 \mathrm{keV}$.

\section{Experimental arrangement}

\subsection{Ge(Li) SPECTROMETER}

The $\mathrm{Ge}(\mathrm{Li})$ spectrometer consisted of the following components: an Ortec $4 \mathrm{~cm}^{2} \times 0.5 \mathrm{~cm}$ detectorcryostat; a Tennelec TC-130 preamplifier and TC-200 amplifier; and a Victoreen (SCIPP) 1600 channel pulse

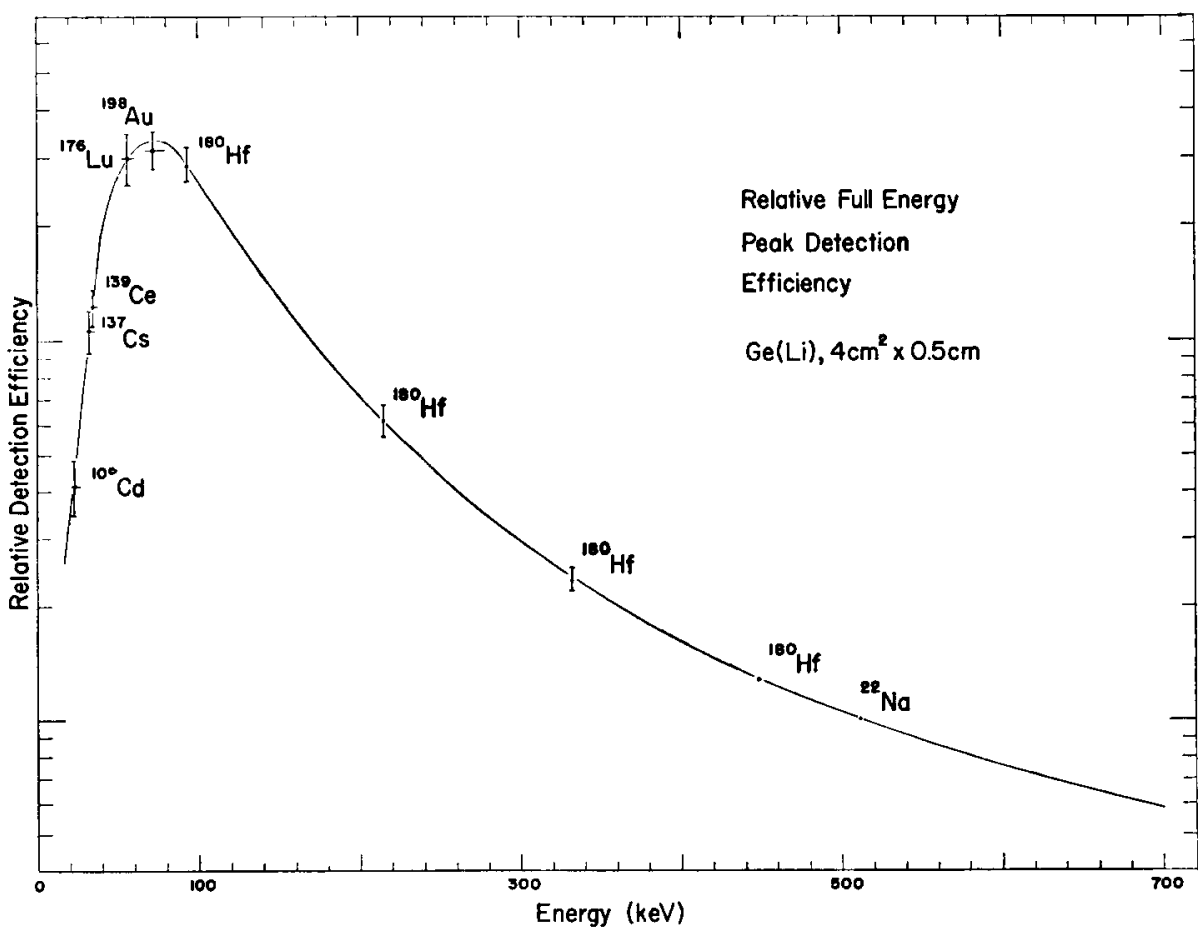

Fig. 1. The relative detection efficiency curve. 
height analyzer. The TC-130 and TC-200 units were modified to include pole-zero cancellation.

\subsection{SOURCES}

The radioactive sources used for this calibration were ${ }^{109} \mathrm{Cd},{ }^{137} \mathrm{Cs},{ }^{139} \mathrm{Ce},{ }^{176} \mathrm{Lu}$ and ${ }^{198} \mathrm{Au}$. The first three of these were purchased commercially; the latter were produced by neutron irradiation in the Ford nuclear reactor. For the calibration, the sources were prepared in a standard manner; the radioactive source material was placed in the depression of a small lucite disk with an eyedropper after having been dissolved or suspended in a liquid. When the liquid was evaporated, the source was covered with scotch tape. Only with the gold source was this procedure modified; the gold solution was placed in a specially prepared glass disk rather than a plastic one since the gold sample was dissolved in aqua regia.

\section{Determination of relative detection efficiency}

The probability for $\mathrm{K} \mathrm{X}$-ray emission following an internal conversion $T_{\mathrm{KX}}(\mathrm{IC})$ is related to the probability for gamma emission $T_{\gamma}$ by

$$
T_{\mathrm{Kx}}(\mathrm{IC}) / T_{\gamma}=\alpha_{\mathrm{K}} \omega_{\mathrm{K}},
$$

TABLE 1

Data used in a determination of the fraction of X-rays associated with the internal conversion process.

\begin{tabular}{|c|c|c|c|c|c|}
\hline Isotope & $\begin{array}{c}\text { K-shell conversion } \\
\text { coefficient }\end{array}$ & $\begin{array}{c}\text { K-shell fluorescent } \\
\text { yield }^{c}\end{array}$ & $\begin{array}{l}\text { Electron capture } \\
\text { ratio }\end{array}$ & $\begin{array}{c}\text { Ratio of }(\mathbf{L}+\mathbf{M}+\ldots) / \mathrm{K} \\
\text { conversions }\end{array}$ & $\begin{array}{l}\text { Rel. emission rates } \\
\qquad T_{\mathrm{Kx}}(\mathrm{IC}) / T_{\gamma}\end{array}$ \\
\hline $\begin{array}{l}{ }^{109} \mathrm{Cd} \\
{ }^{139} \mathrm{Ce}\end{array}$ & $\begin{array}{c}11.0 \pm 0.3^{\mathrm{a}} \\
0.2142 \pm 0.0015^{b}\end{array}$ & $\begin{array}{l}0.84 \\
0.91\end{array}$ & $\begin{aligned} 0.228 & \pm 0.003^{\mathrm{a}} \\
0.37 & \pm 0.02^{\mathrm{d}}\end{aligned}$ & $\begin{array}{c}1.25 \pm 0.13^{\mathrm{a}} \\
0.146 \pm 0.010^{\mathrm{e}}\end{array}$ & $\begin{array}{c}9.24 \pm 0.27 \\
0.1949 \pm 0.0038\end{array}$ \\
\hline Isotope & $\begin{array}{l}\text { Prob. for K X-rays due } \\
\text { to elec. cap. per } \\
\text { elec. cap. } \\
T_{\mathrm{k} \times(\mathrm{EC}) / T(\mathrm{EC})}\end{array}$ & & $\begin{array}{l}\text { Ratio of prob. for } \\
\text { elec. cap. to prob. for } \\
\text { gamma emission } \\
T(E C) / T_{\gamma}\end{array}$ & $\begin{array}{l}\text { Ratio of prob. for } \mathrm{K} \\
\mathrm{X} \text {-ray due to elec. cap } \\
\text { to prob. for } \\
\text { gamma emission } \\
T_{\mathrm{I} \times}(\mathrm{EC}) / T_{\gamma}\end{array}$ & $\begin{array}{c}\text { Fraction of } \mathrm{K} X \text {-rays } \\
\text { due to int. conv. } \\
T_{\mathrm{KX}}(\mathrm{IC}) / T_{\mathrm{KX}}\end{array}$ \\
\hline $\begin{array}{l}{ }^{109} \mathrm{Cd} \\
{ }^{139} \mathrm{Ce}\end{array}$ & $\begin{array}{c}0.684 \pm 0.013 \\
0.66 \pm 0.16\end{array}$ & & $\begin{array}{c}25.8 \pm 1.7 \\
1.246 \pm 0.017\end{array}$ & $\begin{array}{l}17.6 \pm 1.2 \\
0.82 \pm 0.22\end{array}$ & $\begin{array}{l}0.344 \pm 0.017 \\
0.192 \pm 0.006\end{array}$ \\
\hline
\end{tabular}

${ }^{a}$ Ref. $\left.{ }^{2}\right)$; ${ }^{b}$ Weighted average ${ }^{3}$ ); ${ }^{c}$ Ref. ${ }^{4}$ ); the errors were considered to be $2 \% ;{ }^{d}$ Ref. ${ }^{5}$ ); ${ }^{\text {e }}$ An average of results taken from ${ }^{5-8}$ ).

TABLE 2

Data used in the detection efficiency calibration.

\begin{tabular}{|c|c|c|c|c|c|c|}
\hline Isotope & $\begin{array}{l}\text { X-ray and } \\
\text { gamma-ray } \\
\text { energiesk }^{k}\end{array}$ & $\begin{array}{l}\text { K-shell } \\
\text { conversion } \\
\text { coefficient }\end{array}$ & $\begin{array}{c}\text { K-shell } \\
\text { fluorescent } \\
\text { yield }\end{array}$ & $\begin{array}{l}\text { Rel. emission } \\
\text { rates } \\
T_{\mathrm{Kx}}(\mathrm{IC}) / T_{\gamma}\end{array}$ & $\begin{array}{c}\text { Avg. full energy } \\
\text { peak area ratio } \\
\qquad A_{\mathrm{x}} / A_{\gamma}\end{array}$ & $\begin{array}{l}\text { Full energy peak } \\
\text { efficiency ratios } \\
\text { RDE }_{k x}(\mathrm{IC}) / \mathrm{RDE}_{\gamma}\end{array}$ \\
\hline${ }^{109} \mathrm{Cd}$ & $\begin{array}{l}22.7 \\
88.033^{\mathrm{a}}\end{array}$ & $11.0 \pm 0.3^{f}$ & 0.84 & 9.24 & $3.297 \times 0.344^{1}$ & $0.123 \pm 0.015$ \\
\hline${ }^{137} \mathrm{Cs}$ & $\begin{array}{l}32.9 \\
661.632^{b}\end{array}$ & $0.09 \pm 0.003 \mathrm{~g}$ & 0.89 & 0.0801 & 1.341 & $16.9 \pm 2.2$ \\
\hline${ }^{139} \mathrm{Ce}$ & $\begin{array}{l}34.2 \\
165.856^{\mathrm{e}}\end{array}$ & $0.2142 \pm 0.0015^{\mathrm{g}}$ & 0.91 & 0.1949 & $1.098 \times 0.192^{1}$ & $1.08 \pm 0.08$ \\
\hline${ }^{176} \mathbf{L u}$ & $\begin{array}{l}57.1 \\
88.36^{\mathrm{a}}\end{array}$ & $1.28 \pm 0.06^{\mathrm{h}}$ & 0.94 & 1.203 & $1.175^{\mathrm{I}}$ & $0.977 \pm 0.088$ \\
\hline${ }^{198} \mathrm{Au}$ & $\begin{array}{l}72.5 \\
411.795^{\mathrm{e}}\end{array}$ & $0.0302 \pm 0.003$ & 0.96 & 0.0290 & 0.600 & $20.9 \pm 1.0$ \\
\hline
\end{tabular}

a Ref. ${ }^{9}$ ).

1) Ref. ${ }^{10}$ ).

c Ref. ${ }^{11}$ ).

Adopted value, ref. ${ }^{12}$ )

e Ref. ${ }^{13}$ ).

( Ref. ${ }^{2}$ ).

$g$ Weighted average, ref. ${ }^{3}$ ).
${ }^{\mathrm{h}}$ Average of results cited in ${ }^{14}$ ),

i Ref. ${ }^{3}$ ).

i Corrected for contributions other than those associated with the conversion of the $88 \mathrm{keV}$ transition.

k Average K X-ray energies taken from ${ }^{15}$ ).

1 The fraction of X-rays associated with the internal conversion process (table 1). 
where $\alpha_{\mathrm{K}}$ is the internal conversion coefficient and $\omega_{\mathrm{K}}$ is the $\mathrm{K}$ fluorescent yield. The relative detection efficiency RDE of the X-rays is related to the RDE of the gamma-rays by

$$
\operatorname{RDE}(\mathrm{X})=\operatorname{RDE}(\gamma) \cdot\left(A_{\mathbf{X}} / A_{\gamma}\right) \cdot\left\{T_{\gamma} / T_{\mathbf{K X}}(\mathrm{IC})\right\},
$$

where $A_{\mathbf{X}} / A_{\gamma}$ is the ratio of peak areas of $\mathrm{K} X$-rays to gamma-rays. The peak area as it is used here has been defined previously $\left.{ }^{1}\right)$; briefly it is $A=\sum_{i}\left(N_{i}-B_{i}\right)$ where $N_{i}$ are the actual number of counts in channel $i$ and $B_{i}$ are the background counts in that channel. (In the present work $B_{i}$ is determined by the straight line separating the peak from the background distribution.)

If the decay is by electron capture, then one must determine what fraction of the observed X-rays are associated with the internal conversion process. The ratio of probabilities for $\mathrm{K} X$-rays associated with electron capture $T_{\mathrm{KX}}(\mathrm{EC})$ to gamma transitions is given by

$$
T_{\mathrm{KX}}(\mathrm{EC}) / T_{\gamma}=\left\{T_{\mathrm{KX}}(\mathrm{EC}) / T_{\mathrm{EC}}\right\} \cdot\left(T_{\mathrm{EC}} / T_{\gamma}\right),
$$

where

$$
T_{\mathrm{KX}}(\mathrm{EC}) / T_{\mathrm{EC}}=\omega_{\mathrm{K}} /\left(1+\varepsilon_{\mathrm{LMN}} / \varepsilon_{\mathrm{K}}\right)
$$

and

$$
T_{\mathrm{EC}} / T_{\gamma}=1+\alpha_{\mathrm{K}}\{1+(\mathrm{L}+\mathrm{M}+\ldots) / \mathrm{K}\} .
$$

Using relations (1) and (3) the fraction of the observed X-rays associated with internal conversion is easily obtained.

The calibration curve in the region $20-700 \mathrm{keV}$ is shown in fig. 1. Since a calibration curve was already established in the energy region above $100 \mathrm{keV}$, the ${ }^{137} \mathrm{Cs},{ }^{139} \mathrm{Ce}$ and ${ }^{198} \mathrm{Au}$ points were placed first. The ${ }^{109} \mathrm{Cd}$ and ${ }^{176} \mathrm{Lu}$ points were then placed so that a

* For example, if a $\mathrm{Cd}$ absorber $0.001 \mathrm{~cm}$ thick was placed in a beam of $20 \mathrm{keV} \mathrm{X-rays,} \mathrm{approximately} 13 \%$ of them would be absorbed or scattered. If a Cd source had the same thickness, then the absorption of X-rays emitted normal to the surface would be reduced to about $7 \%$. The thickness of the ${ }^{109} \mathrm{Cd}$ source used in this calibration did not exceed $0.001 \mathrm{~cm}$. smooth curve could be drawn through the set. The pertinent data for the calibration are given in tables 1 and 2 . In fig. 1 the horizontal bars through the points show the range of energy of the $\mathrm{K} \mathrm{X}$-rays. The errors in fig. 1 and table 2 are based on the specified uncertainties of the quantities used to calculate the relative detection efficiency. Corrections due to source thickness are not included. However, the errors due to source absorption (even in the more unfavorable cases) are probably of the order of $5 \%$ or less*. Consequently, the overall uncertainty in the portion of the curve from $20-100 \mathrm{keV}$ is about $15 \%$.

One of us (DD) would like to thank Professor J. J. Reidy and J. Pearl for their helpful comments.

\section{References}

1) D. P. Donnelly, H. W. Baer, J. J. Reidy and M. L. Wiedenbeck, Nucl. Instr. and Meth. 57 (1967) 219.

2) H. Leutz, K. Schneckerberger and H. Wenniger, Nuclear Physics 63 (1965) 263.

3) B. Van Nooijen and J. H. Hamilton, in Internal conversion processes (ed. J. H. Hamilton; Academic Press, New York, 1966) p. 642.

4) R. W. Fink, R. C. Jopson, H. Mark and C. D. Swift, Rev. Mod. Phys. 38 (1966) 513.

5) B. H. Ketelle, H. Thomas and A. R. Brosi, Phys. Rev. 96 (1954) 1340.

6) A. C. G. Mitchell and E. Hebb, Phys. Rev. 95 (1954) 727.

7) C. H. Pruitt and R. G. Wilkinson, Phys. Rev. 96 (1954) 1340.

${ }^{8}$ ) B. S. Dzhelopov, B. K. Preobrazhenskii, I. M. Rogachev and P. A. Tishkin, Izvest. Akad. Nauk SSSR, Ser. Fiz. 22 (1958) 931; Coulomb. Tech. Transl. 22 (1958) 923.

9) C. G. Diethrich, private communication.

10) R. L. Graham, G. T. Ewan and J. S. Geiger, Nucl. Instr. and Meth. 9 (1960) 245.

11) H. W. Baer, private communication.

12) Nuclear Data Sheets, National Academy of Sciences, National Research Council, Washington 25, D.C.

13) G. Murray, R. L. Graham and J. S. Geiger, Nuclear Physics 45 (1963) 177.

14) A. Artna, in Internal conversion processes (ed. J. H. Hamilton; Academic Press, New York, 1966) p. 303.

15) A. H. Wapstra, G. H. Nijgh and R. van Lieshout, Nuclear Spectroscopy Tables (North-Holland Publishing Co., Amsterdam, 1959). 